\title{
QUEEN'S
UNIVERSITY
BELFAST
}

\section{Epidemiologic Analysis of Asteroid Hyalosis and Associations: The Gutenberg Health Study}

Elbaz, H., Schuster, A. K., Nickels, S., Nagler, M., Ponto, K. I., Münzel, T., Wild, P. S., Beutel, M. E.,

Schmidtmann, I., Lackner, K. J., Pfeiffer, N., \& Peto, T. (2021). Epidemiologic Analysis of Asteroid Hyalosis and Associations: The Gutenberg Health Study. Ophthalmology, 128(2), 328-330. https://doi.org/10.1016/j.ophtha.2020.07.008

Published in:

Ophthalmology

Document Version:

Peer reviewed version

Queen's University Belfast - Research Portal:

Link to publication record in Queen's University Belfast Research Portal

\section{Publisher rights}

Copyright 2020 Elsevier Ltd.

This manuscript is distributed under a Creative Commons Attribution-NonCommercial-NoDerivs License

(https://creativecommons.org/licenses/by-nc-nd/4.0/), which permits distribution and reproduction for non-commercial purposes, provided the author and source are cited.

\section{General rights}

Copyright for the publications made accessible via the Queen's University Belfast Research Portal is retained by the author(s) and / or other copyright owners and it is a condition of accessing these publications that users recognise and abide by the legal requirements associated with these rights.

Take down policy

The Research Portal is Queen's institutional repository that provides access to Queen's research output. Every effort has been made to ensure that content in the Research Portal does not infringe any person's rights, or applicable UK laws. If you discover content in the Research Portal that you believe breaches copyright or violates any law, please contact openaccess@qub.ac.uk. 


\section{Epidemiology of asteroid hyalosis and associations: the Gutenberg}

\section{Health Study}

3 Elbaz, $\mathrm{H}^{1,2}$ Schuster $\mathrm{AK},{ }^{1}$ Nickels $\mathrm{S},{ }^{1}$ Nagler $\mathrm{M},{ }^{3}$ Ponto $\mathrm{KI},{ }^{1}$ Münzel T, ${ }^{6}$ Wild PS, $, 3,4$ 4 Beutel ME, ${ }^{7}$ Schmidtmann ${ }^{,},{ }^{8}$ Lackner KJ, ${ }^{9}$ Pfeiffer $\mathrm{N}^{1,}{ }^{*}$, Tunde Peto ${ }^{10,11}{ }^{*}$

${ }^{1}$ Department of Ophthalmology, University Medical Center of the Johannes Gutenberg-University Mainz,

7 Mainz, Germany

$8 \quad{ }^{2}$ Department of Ophthalmology, Otto von Guericke University Magdeburg, Germany

$9{ }^{3}$ Preventive Cardiology and Preventive Medicine, Center for Cardiology, University Medical Center of the 10 Johannes Gutenberg-University Mainz, Mainz, Germany

$11{ }^{4}$ Center for Thrombosis and Hemostasis, University Medical Center of the Johannes Gutenberg-University

12 Mainz, Mainz, Germany;

$13{ }^{5}$ DZHK (German Center for Cardiovascular Research), partner site Rhine-Main, Mainz, Germany

$14{ }^{6}$ Center for Cardiology, Cardiology I, University Medical Center Mainz, Mainz, Germany

$15{ }^{7}$ Department of Psychosomatic Medicine and Psychotherapy, University Medical Center Mainz, Mainz,

16 Germany

$17{ }^{8}$ Department of Biomedical Statistics, University Medical Center of the Johannes Gutenberg-University

18 Mainz, Mainz, Germany

199 Institute of Clinical Chemistry and Laboratory Medicine, University Medical Center Mainz, Mainz, Germany

$20{ }^{10}$ NIHR Biomedical Research Centre at Moorfields Eye Hospital NHS Foundation Trust and UCL Institute of

21 Ophthalmology

$22{ }^{11}$ Department of Ophthalmology, Centre for Public Health, Institute of Clinical Sciences, School of Medicine,

23 Queen's University Belfast, Belfast, United Kingdom.

* shared last

Conflict of interest: None of the authors has a conflict of interest concerning the study.

29 Financial support: The Gutenberg Health Study is funded through the government of RhinelandPalatinate („Stiftung Rheinland-Pfalz für Innovation“, contract AZ 961-386261/733), the research programs "Wissenschafft-Zukunft" and "Center for Translational Vascular Biology (CTVB)" of the Johannes Gutenberg-University of Mainz, and its contract with Boehringer Ingelheim and PHILIPS

33 Medical Systems, including an unrestricted grant for the Gutenberg Health Study. Schuster AK holds

34 the professorship for ophthalmic healthcare research endowed by "Stiftung Auge " and endowed by 
36 e.V." He received research funding from Allergan, Bayer Vital, Novartis and Heidelberg Engineering.

37 Philipp S. Wild is funded by the Federal Ministry of Education and Research (BMBF 01EO1503) and

38 he is $\mathrm{PI}$ of the German Center for Cardiovascular Research (DZHK). The sponsors and funding

39 organizations had no role in the design or conduct of this research.

40

41

42 Corresponding Author and reprint requests:

43 Dr. med. Hisham Elbaz

44 Email: hisham elbaz@yahoo.com

45

46

47

48

49

50

51

52

53

54

55

56

57

58

59

60

61

62 
63 Asteroid hyalosis $(\mathrm{AH})$ was first described by Benson in 1894 who called it asteroid hyalitis.

64 The condition is mostly unilateral and rarely impairs vision. It is seen as white, creamy, iridescent particles moving around in the vitreous following eye movement. Within this work, we are reporting on the prevalence, incidence and associations of asteroid hyalosis.

67 The Gutenberg Health Study (GHS) is a population-based, prospective, observational cohort 68 study in the Rhine-Main Region in Germany. The baseline study examined 15,010 subjects 69 aged between 35 and 74 between 2007 and 2012. Of these, 12.423 participants (82.8\% of baseline) attended the 5-year follow-up between 2012 and 2017 . The sample was drawn

71 randomly from local governmental registry and the cohort was equally stratified by sex, residence and per each decade of age..$^{1,2}$

73 All subjects underwent a general medical examination including an analysis of the 74 cardiovascular risk factors as well as an ophthalmological examination including history and 75 other tests including autorefraction, visual acuity and measurement of intraocular pressure. 76 Slitlamp biomicroscopy including fundus examination was conducted. Fundus images were 77 taken with a non-mydriatic fundus camera (Visucam PRO NMTM, Carl Zeiss AG, Jena, 78 Germany) in a darkened room with the pupil's natural width. Three photographs were taken 79 of each eye: at $30^{\circ}$ and $45^{\circ}$ centred on the optic nerve, and at $30^{\circ}$ centred on the macula.

80 The grading of the baseline and five-year follow-up fundus images was based on the 81 detection of creamy white vitreal lesions typical of $\mathrm{AH}$. Incident $\mathrm{AH}$ was defined as the first 82 appearance of $\mathrm{AH}$ in either eye of subjects who had no sign of $\mathrm{AH}$ at the baseline visit in 83 both eyes. Intra-rater and inter-rater reliability showed high agreement.

84 The study protocol and study documents were approved by the local ethics committee of 85 the Medical Chamber of Rhineland-Palatinate in Germany. According to the tenets of the 86 Declaration of Helsinki, written informed consent was obtained from all subjects prior to 87 entering the study. 
88 Statistical analysis included quality controls and an estimation of prevalence and incidence

89 including 95\% confidence intervals. Logistic regression analysis with generalized estimating

90 equations was computed to evaluate whether $\mathrm{AH}$ was associated with spherical equivalent,

91 intraocular pressure and visual acuity adjusted for age and sex. Another model was computed using logistic regression analysis on person-level ( $\mathrm{AH}$ in at least one eye) to evaluate associated systemic diseases and other risk factors including age, sex, arterial

94 hypertension, diabetes, smoking, alcohol intake and family history of myocardial infarction 95 and stroke.

Baseline fundus photographs were available in 12,779 (85.1\%) of 15,010 GHS subjects. The baseline cohort included 6,398 (50\%) men and 6,381 (50\%) women. The mean age in the whole cohort $54.9 \pm 11.1$ years. The study characteristics is described in supplemental 99 table 1 available at www.aaojournal.org. AH was seen in $61(0.48 \%)$ participants (74 eyes). 10032 subjects had $\mathrm{AH}$ in the right eye, 42 in the left eye. 13 subjects $(21.3 \%)$ had bilateral 101 lesions, whereas 48 subjects $(78.7 \%)$ had unilateral involvement. The mean age of the 102 subjects having $\mathrm{AH}$ was $66.2 \pm 7.6$ years versus $54.9 \pm 11.1$ years in subjects without $\mathrm{AH}$. The 103 unweighted prevalence was $0.48 \%(\mathrm{Cl}: 0.37 \%-0.61 \%)$. The systemic associations of $\mathrm{AH}$ 104 are summarized in Table 1: Increased age $(O R=1.13$ per year, $p<0.001)$, male sex $105(\mathrm{OR}=1.71, \mathrm{p}=0.05)$, and diabetes $(\mathrm{OR}=2.25, \mathrm{p}=0.007)$. The prevalence of $\mathrm{AH}$ increased 106 with age: $0.04 \%$ at $35-44$ years while $1.3 \%$ at $65-74$ years (Supplemental table 2 available 107 at www.aaojournal.org).

108 Of 12,779 baseline participants, 8,176 subjects were followed-up after five years. Incident $109 \mathrm{AH}$ was identified in 17 participants (19 eyes) with a 5-year cumulative incidence of $0.2 \%$ 110 (95\%-Cl:0.11\%- 0.32\%) which was higher in men 0.27\% (95\%-Cl: $0.13 \%-0.47 \% ; n=11$ 111 subjects) than in women $0.15 \%(95 \%-\mathrm{Cl}: 0.055 \%, 0.32 \%, \mathrm{n}=6$ subjects). The incidence 112 ranged from $0 \%$ in the group aged $35-44$ years to $0.77 \%$ in the group aged $65-74$ years. In 
113 the 27 subjects with unilateral $\mathrm{AH}$ at baseline: 3 unaffected fellow eyes $(11 \%)$ showed $\mathrm{AH}$ 114 within 5 years.

115 The prevalence of $\mathrm{AH}$ in the GHS of $0.5 \%$ was similar to that reported from the Yonsei Eye

116 Study in South Korea $(0.36 \% \text {; subjects aged } \geq 40 \text { years })^{3}$. It was lower than the $1.0 \%$

117 reported in the Blue Mountains Eye study (participants aged 49-97 years) ${ }^{4}$ and the $0.83 \%$

118 from a cross sectional study in the USA (average age 70 years) ${ }^{5}$. However, our age-stratified 119 prevalence values matched the reported data from the Blue Mountains Eye Study ${ }^{4}(0 \%$ in 120 persons aged $<55$ years, $0.4 \%$ in persons aged $55-64$ years, $1.1 \%$ in persons aged $65-74$

121 years and $2.1 \%$ among those aged more than 75 years), compared to $0.39 \%$ in persons

122 aged $55-64$ years and $1.3 \%$ in those aged $65-74$ years in our study. Also, age-stratified data 123 from the Yonsei Study $^{3}(0.05 \%$ at age $40-49$ years, $0.42 \%$ at age $50-59$ years, $0.89 \%$ at age 12460 to 69 years and $1.18 \%$ at age 70 and older) and from the Beaver Dam Eye Study6 (about $1250.2 \%$ at age $43-54$ years, $1.1 \%$ at age 55-64 years, 1.\% at age 65 to 74 years) were in line 126 with our results.

127 The association of $\mathrm{AH}$ with diabetes mellitus in our study is in line with the positive 128 association reported in previous studies. However, the association between diabetes and 129 AH was substantially attenuated from a univariate OR of 3.88 to an OR of $1.99[1.12 ; 3.53]$ 130 after adjustment for sex and age. Association between $\mathrm{AH}$ and diabetes mellitus could be 131 explained by the increased permeability of basal membranes in diabetic eyes which are 132 likely to be the source of phospholipid and calcium needed for asteroid formation ${ }^{7}$. 133 Therefore, testing for diabetes in patients showing $\mathrm{AH}$ should be considered.

134 In summary, the prevalence of $\mathrm{AH}$ in the GHS is estimated as $0.5 \%$ and is associated with 135 advanced age, male sex and diabetes in Europe, while the cumulative 5-year incidence is 136 estimated as $0.2 \%$. 


\section{References:}

140 1. Höhn R, Kottler U, Peto T, et al. The Ophthalmic Branch of the Gutenberg Health

141 Study: Study Design, Cohort Profile and Self-Reported Diseases. PLoS One. $142 \quad$ 2015;10(3):e0120476. doi:10.1371/journal.pone.0120476

143 2. Mirshahi a, Ponto K a, Höhn R, Wild PS, Pfeiffer N. [Ophthalmological aspects of the 144 Gutenberg Health Study (GHS): an interdisciplinary prospective population-based cohort study]. Ophthalmologe. 2013;110(3):210-217. doi:10.1007/s00347-012-26660

4. Mitchell P, Wang MY, Wang JJ, Wang MY. Asteroid hyalosis in an older population : the Blue Mountains Eye Study Original article Asteroid hyalosis in an older population : the Blue Mountains Eye Study. 2016;6586(April). doi:10.1076/opep.10.5.331.17324

5. Bergren R, Brown G, Duker J. Prevalence and association of asteroid hyalosis with systemic diseases. Am J Ophthalmol. 1991;111:289-293. doi:10.1016/S0002-

6. Moss SE, Klein R, Klein BE. Asteroid hyalosis in a population: the Beaver Dam eye study. Am J Ophthalmol. 2001;132(1):70-75. doi:10.1016/s0002-9394(01)00936-9

7. Chakrabarti S, Ma N, Sima AA. Anionic sites in diabetic basement membranes and their possible role in diffusion barrier abnormalities in the BB-rat. Diabetologia. 1991;34(5):301-306. doi:10.1007/bf00405000 
164 Table 1: Association analysis of baseline asteroid hyalosis with systemic diseases and other 165 potential risk factors. Multivariable logistic regression analysis was conducted. Data from 166 the Gutenberg Health Study (2007-2012; n=12.747)

167

168 Supplemental Table 1: Characteristics of the analysis sample. Data from the population169 based German Gutenberg Health Study (2007-2012).

170

171 Supplemental Table 2: Age-related prevalence and 5-year cumulative incidence of Asteroid 172 Hyalosis

173 